\title{
Effect of etelcalcetide on cardiac hypertrophy in hemodialysis patients: a randomized controlled trial (ETECAR-HD)
}

\author{
Katharina Dörr ${ }^{1}$, Michael Kammer ${ }^{1,2}$, Roman Reindl-Schwaighofer ${ }^{1}$, Matthias Lorenz ${ }^{3}$, Christian Loewe ${ }^{4}$, \\ Rodrig Marculescu ${ }^{5}$, Reinhold Erben ${ }^{6}$ and Rainer Oberbauer ${ }^{1^{*}}$
}

\begin{abstract}
Background: Fibroblast growth factor 23 (FGF23) is associated with left ventricular hypertrophy (LVH) in patients with chronic kidney disease, and calcimimetic therapy reduces plasma concentrations of FGF23. It remains unknown whether treatment with the calcimimetic etelcalcetide $(E T L)$ reduces $L V H$ in patients on hemodialysis.

Methods/design: This single-blinded randomized trial of 12 months duration will test the effects of ETL compared with alfacalcidol on LVH and cardiac fibrosis in maintenance hemodialysis patients with secondary hyperparathyroidism. Both treatment regimens will be titrated to equally suppress secondary hyperparathyroidism while alfacalcidol treatment causes an increase and ETL a decrease in FGF23, respectively.

Patients treated thrice weekly with hemodialysis for $\geq 3$ months and $\leq 3$ years with parathyroid hormone levels $\geq 300$ $\mathrm{pg} / \mathrm{ml}$ and LVH will be enrolled in the study.

The primary study endpoint is change from baseline to 12 months in left ventricular mass index (LVMl; $\left.\mathrm{g} / \mathrm{m}^{2}\right)$ measured by cardiac magnetic resonance imaging. Sample size calculations showed that 62 randomized patients will be necessary to detect a difference in LVMI of at least $20 \mathrm{~g} / \mathrm{m}^{2}$ between the two groups at 12 months. Due to the strong association of volume overload and LVH, randomization will be stratified by residual kidney function, and regular body composition monitoring will be performed to control the volume status of patients.

Study medication will be administered intravenously by the dialysis nurses after every hemodialysis session, thus omitting adherence issues.

Secondary study endpoints are cardiac parameters measured by echocardiography, biomarker concentrations of bone metabolism (FGF23, vitamin D, parathyroid hormone, calcium, phosphate, s-Klotho), cardiac markers (pro-brain natriuretic peptide, pre- and postdialysis troponin $\mathrm{T}$ ) and metabolites of the renin-angiotensin-aldosterone cascade (angiotensin I (Ang I), Ang II, Ang-(1-7), Ang-(1-5), Ang-(1-9), and aldosterone).

Discussion: The causal inference and pathophysiology of LVH regression by FGF23 reduction using calcimimetic treatment has not yet been shown. This intervention study has the potential to discover a new strategy for the treatment of cardiac hypertrophy and fibrosis in patients on maintenance hemodialysis. It might be speculated that successful treatment of cardiac morphology will also reduce the risk of cardiac death in this population.
\end{abstract}

Trial registration: European Clinical Trials Database, EudraCT number 2017-000222-35; ClinicalTrials.gov, NCT03182699. Registered on

Keywords: Hemodialysis, Left ventricular hypertrophy, Secondary hyperparathyroidism, FGF23, Etelcalcetide, Alfacalcidol

\footnotetext{
* Correspondence: Rainer.oberbauer@meduniwien.ac.at

${ }^{1}$ Department of Nephrology, Medical University of Vienna, Spitalgasse 23,

1090 Vienna, Austria

Full list of author information is available at the end of the article
}

(c) The Author(s). 2019 Open Access This article is distributed under the terms of the Creative Commons Attribution 4.0 International License (http://creativecommons.org/licenses/by/4.0/), which permits unrestricted use, distribution, and reproduction in any medium, provided you give appropriate credit to the original author(s) and the source, provide a link to the Creative Commons license, and indicate if changes were made. The Creative Commons Public Domain Dedication waiver (http://creativecommons.org/publicdomain/zero/1.0/) applies to the data made available in this article, unless otherwise stated. 


\section{Background}

Patients with chronic kidney disease (CKD) develop left ventricular hypertrophy $(\mathrm{LVH})$ and cardiac fibrosis which contributes to congestive heart failure, diastolic dysfunction, arrhythmia and sudden death [1-3]. The majority of patients with terminal renal failure treated by dialysis exhibit LVH and have a dramatically increased risk of sudden cardiac death [4].

The main drivers of cardiac remodeling in hemodialysis patients are chronic volume overload, intradialytic weight gain and hemodynamic fluctuations during hemodialysis treatment $[5,6]$. Additional factors include elevated fibroblast growth factor 23 (FGF23) levels in CKD and dialysis patients and angiotensin II (Ang II)-mediated cardiac remodeling $[7,8]$. Circulating concentrations of FGF23 increase progressively as the glomerular filtration rate declines, beginning as early as CKD stage 3b [9-14]. The biological effects of FGF23 are mediated through a receptor complex consisting of FGF receptors (FGFRs) and of the co-receptor $\alpha$-Klotho, which enables proper FGF23 signaling in target tissues such as the kidney [15].

The left ventricular mass index (LVMI) rises with increasing FGF23 as does the prevalence of eccentric and concentric hypertrophy [2]. The pathophysiological mechanism by which FGF23 may cause LVH is still not well understood and two potentially synergistic hypotheses are discussed in the scientific community.

Wolf et al. showed a direct effect of FGF23 on myocardial hypertrophy. FGF23 treatment of isolated neonatal mouse cardiomyocytes caused an increase in surface area and an activation of pro-hypertrophic gene programs that was independent of Klotho and mediated through FGFR4 $[1,2,16]$.

Andrukhova et al. proposed a complementary concept by stating that FGF23-induced $\mathrm{Na}^{+}$and $\mathrm{Ca}^{2+}$ retention, volume overload and hypertension are the most determinant factors underlying the pro-hypertrophic effects [17-19]. The investigators were able to show that a lowdose anti-FGF23 antibody treatment substantially ameliorated disease progression and left ventricular dysfunction by preventing the abovementioned volume overload and its consequences on the circulation (unpublished data). Additionally, they showed that the administration of chlorothiazide completely prevents FGF23-induced volume expansion and heart hypertrophy [17].

Recently, Slavic et al. provided evidence of increasing levels of FGF23 and Klotho in a mouse model with pressure overload-induced LVH. They identified aldosterone to be an important stimulator of bone FGF23 transcription following pressure overload [20].

The association of FGF23 and LVH via an activation of the renin-angiotensin-aldosterone system (RAAS) through suppression of angiotensin-converting enzyme 2 (ACE2), and therefore increasing its product Ang-(1-7), have been described previously [21-29]. An overactive RAAS has been linked to multiple pathological processes such as LVH and heart failure, and medications inhibiting the RAAS are capable of improving both [7, 8, 30-32].

The HEMO study investigated a cohort of 1340 hemodialysis patients and found that higher FGF23 levels were a predictor of cardiac events, infections and all-cause mortality [33]. Various studies, such as PARADIGM, demonstrated that the oral calcimimetic drug cinacalcet causes a reduction in the level of FGF23 of at least 30\%, while the intake of vitamin D analogs causes an increase of over $40 \%$. Both treatments cause similar modest reductions in parathyroid hormone (PTH) levels [34-37].

In this trial, the level of FGF23 will be modified by either the calcimimetic etelcalcetide (ETL) or alfacalcidol (ALFA) at a PTH clamp, and therefore will be able to test the causality of FGF23 reduction on cardiac hypertrophy and fibrosis.

\section{Methods/design Study design}

In this randomized, controlled, single-blinded trial, we will study the effect of the calcimimetic drug ETL in comparison with the active vitamin D ALFA on LVH and cardiac fibrosis in hemodialysis patients with secondary hyperparathyroidism (sHPT).

The treatment will be administered intravenously by dialysis nurses in addition to conventional HPT therapy (phosphate binders, calcium supplementation) in $62 \mathrm{sub}-$ jects for 12 months. LVH will be measured as LVMI by cardiac magnetic resonance imaging (cMRI). The inclusion and exclusion criteria for participants are listed in Table 1. Patients will be recruited from two hemodialysis centers of the Medical University of 144 Vienna with 160 prevalent patients and the Vienna Dialysis Center with 300 prevalent 145 patients. The present protocol follows the Standard Protocol Items: Recommendations for Interventional Trials (SPIRIT) guidelines and fulfills the SPIRIT checklist (see Additional file 1).

\section{Screening, washout phase and randomization}

The study flow chart and design are presented in Figs. 1 and 2, respectively. Following signed informed consent, patients will be screened for LVH (i.e., interventricular septum thickness $\geq 12 \mathrm{~mm}$ ) and cardiac fibrosis using strain echocardiography. Volume status and fluid composition will be explored with the help of body composition monitoring (BCM) and lung ultrasound [38-41]. Only patients who are stable at their dry weight are eligible for enrollment to the study. All patients that are already being treated with a calcimimetic drug or vitamin $\mathrm{D}$ therapy will undergo a 4-week-long washout phase in which the treatment will be discontinued. Study participants 
Table 1 Main inclusion and exclusion criteria

\begin{tabular}{l} 
Main inclusion criteria \\
Age $\geq 18$ years \\
Maintenance hemodialysis $3 \times /$ week for $\geq 3$ months and $\leq 3$ years \\
SHPT defined by: \\
• PTH $\geq 300 \mathrm{pg} / \mathrm{mL}$ and no prior calcimimetic drug, or \\
• PTH $\geq 300 \mathrm{pg} / \mathrm{mL}$ after washout of vitamin D for 4 weeks \\
• Patients after washout of cinacalcet for 4 weeks \\
Serum calcium $\geq 2.08$ mmol/L \\
LVH \pm cardiac fibrosis on echocardiography \\
Optimal fluid composition (BCM measurement); pulmonary edema \\
excluded (lung ultrasound) \\
No substantial dose change of calcium supplements, phosphate \\
binders, dialysate calcium, or active vitamin D for 4 weeks before \\
screening \\
Main exclusion criteria \\
Unstable medical condition \\
Significantly impaired LV systolic function or hemodynamically \\
effective heart valve defects \\
Anticipated parathyroidectomy \\
Scheduled kidney transplant from a living donor \\
Uncontrolled hyperphosphatemia \\
Active participation in another clinical trial \\
Sensitivity or intolerance to administered products \\
Women who are pregnant or breast feeding \\
Disorder compromising the ability to give informed consent and/or \\
to comply with the study procedures \\
Contraindications for MRI \\
\hline
\end{tabular}

$B C M$ body composition monitoring, $L V$ left ventricular, $L V H$ left ventricular hypertrophy, MRI magnetic resonance imaging, PTH parathyroid hormone, sHPT secondary hyperparathyroidism

who qualify for the study will be randomized at a 1:1 ratio to the ETL group or the ALFA group. Randomization will be performed by a computer algorithm (www.meduniwien.ac.at/randomizer/web) and will be stratified by residual kidney function $(<500 \mathrm{ml}$ versus $\geq 500 \mathrm{ml}$ urine per day) and the center where patients are recruited (Medical University of Vienna versus Vienna Dialysis Center). To ensure that comparison groups will be of approximately the same size and balanced in each center, a block randomization (block size of 4) will be used.

\section{Treatment phase}

The treatment phase starts with a dose-titration phase of 16 weeks. Subjects will be considered for dose titration of the investigational product every 4 weeks. Dose adjustment will be based upon PTH values, serum electrolytes and safety assessment. Study visits will take place in 2 -week intervals during the first 10 weeks of treatment followed by study visits every 4 weeks. The duration of the treatment phase is 12 months.

\section{Study endpoints}

The primary endpoint is the change in LVMI (quantified in grams per meter squared) from baseline to 12 months between the ETL and ALFA groups as assessed by cMRI.

Secondary endpoints are the change in left atrial diameter (measured in millimeters), the change in LVMI and left atrial diameter progression (percent), the difference in cardiac fibrosis and fibrosis progression as measured with noncontrast T1 mapping (milliseconds) and differences in cardiac function (ejection fraction, measured as percent) as well as wall motion abnormalities (percent change) as measured by cMRI and strain echocardiography after 1year treatment with either drug. Other secondary objectives include changes in serum levels of FGF23, s-Klotho, PTH, 25-hydroxyvitamin D (25(OH)D) and 1,25-dihydroxyvitamin $\mathrm{D}\left(1,25(\mathrm{OH})_{2} \mathrm{D}\right)$, phosphate, calcium, probrain natriuretic peptide (proBNP), pre- and postdialysis troponin $\mathrm{T}(\mathrm{TnT})$ and the metabolites of the RAAS cascade (Ang I, Ang II, Ang-(1-7), Ang-(1-5), Ang-(1-9), aldosterone) under either treatment as well as their association with the abovementioned cardiac changes.

\section{Outcome measurements Cardiac MRI}

Two cMRIs are planned for each patient. The baseline MRI will take place before randomization and the second MRI will take place after completing 12 months of treatment. Both will be carried on the dialysis-free day.

The cMRI will be analyzed by one radiologist blinded to the treatment allocation. Noncontrast cMRI will be carried out using a 1.5-Tesla MRI scanner (Siemens Avanto $1.5 \mathrm{~T}$, Siemens, Erlangen, Germany). Axial black-blood imaging will be performed for visualization of cardiac anatomy. For the assessment of cardiac function, left ventricular muscle mass, and the visualization of possible wall motion abnormalities, multislice-multiphase cine imaging will be performed in the long horizontal axis as well as in the short axis view through the entire heart. The ejection fraction (in percent) of both the left and right ventricles will be calculated in a semiautomatic fashion using dedicated software (Siemens Argus) based on the short axis views. For the assessment of cardiac function, the enddiastolic and end-systolic volume (in milliliters) will be assessed in a semiautomatic fashion and the left ventricular muscle mass will be calculated [42]. The upper limit of normal left ventricular mass indexed for body surface area (LVM/BSA) values is considered to be $84.1 \mathrm{~g} / \mathrm{m}^{2}$ for male and $76.4 \mathrm{~g} / \mathrm{m}^{2}$ for female subjects [6]. 


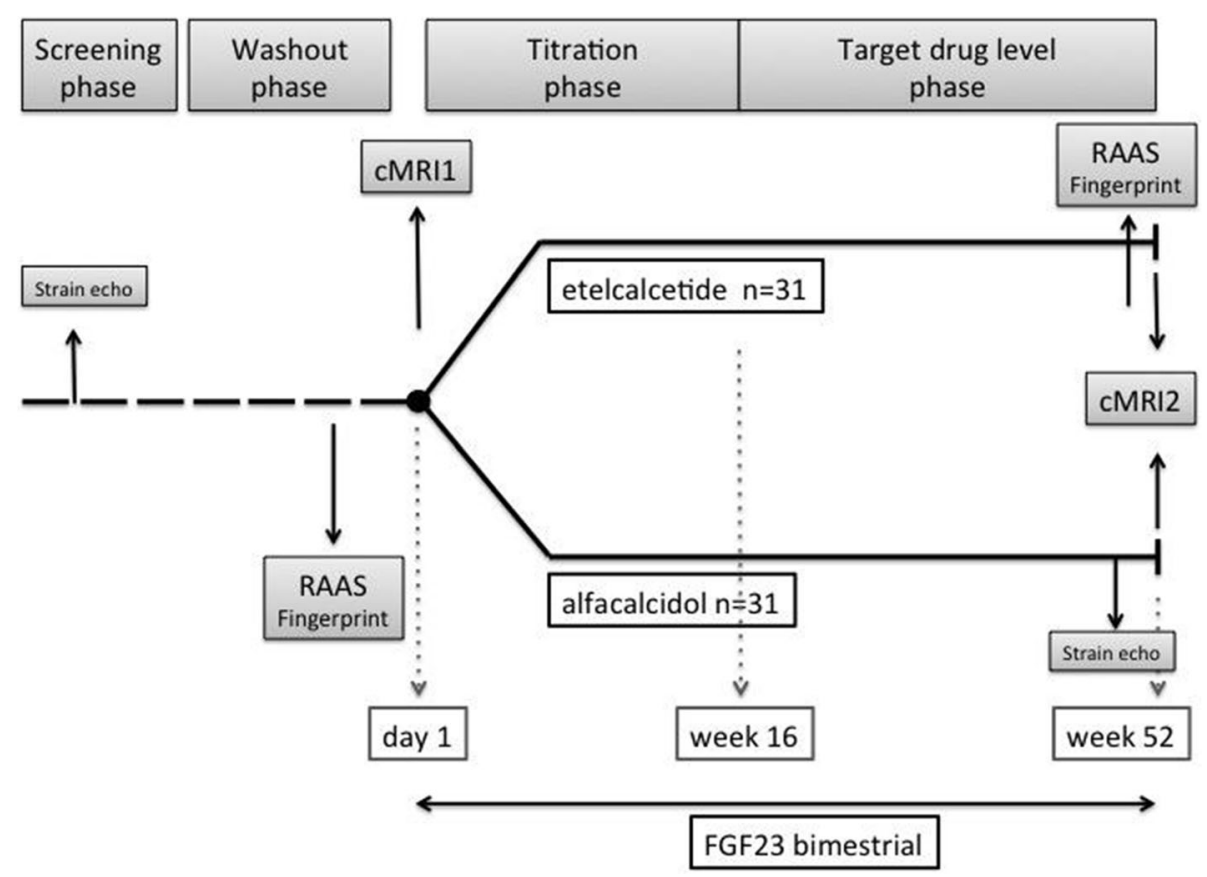

Fig. 1 Study flow chart. cMRI cardiac magnetic resonance, Echo echocardiography, FGF23 fibroblast growth factor 23, RAAS renin-angiotensin-aldosterone system

For the detection of myocardial fibrosis, fat-suppressed T2-weighted edema-sensitive imaging will be performed. Noncontrast T1 mapping will be performed to detect diffuse fibrotic processes ( $\mathrm{T} 1$ time is measured in milliseconds for global, septal and nonseptal times). The native myocardial $\mathrm{T} 1$ relaxation is a surrogate of myocardial fibrosis [43]. In hemodialysis patients the interventricular septum appears to be particularly prone to the development of fibrosis [44].

\section{Strain echocardiography}

Echocardiography for the evaluation of LVH will take place during screening as well as at the end of the treatment phase. Doppler imaging or two-dimensional speckle tracking echocardiography is used to measure strain and strain rate. With these techniques subclinical heart disease in fibrotic processes can be detected, with the predominant planes of strain that are initially affected mirroring the histological location of early fibrosis $[45,46]$. Global longitudinal strain is measured as percent and correlates well with myocardial fibrosis [47]. The physician performing the examination will be blinded to the patient's treatment assignment.

\section{Body composition monitoring}

$\mathrm{BCM}$ will be performed during screening and will be repeated at 2-month intervals. BCM measurements are based on bioimpedance spectroscopy. The measurements are fed into a model to measure overhydration of an individual [41]. Fluid overload assessed by BCM is expressed as an absolute value in liters or as a relative value as a percent [48]. It is a reproducible body fluid volume determination over a wide range of body compositions at different states of health and disease [40]. Only patients who achieve their optimal dry weight at the end of dialysis treatment and tolerate it well will be enrolled in the study. Should patients present themselves with hypervolemia as measured by $\mathrm{BCM}$ during the treatment phase, the dry weight will be adapted dependent on $\mathrm{BCM}$ results in accordance with clinical judgment and standard of care equally in both treatment groups.

\section{Lung ultrasound}

The assessment of extravascular lung water will take place as part of the screening procedures with the help of lung ultrasound, which can visualize lung edema and classify it semiquantitatively [38, 39, 49]. Only patients without signs of pulmonary edema will be enrolled in the study.

\section{Laboratory analyses}

Biochemical data will be collected prior to hemodialysis at baseline and periodically (e.g., intact PTH, calcium, phosphate, $25(\mathrm{OH}) \mathrm{D}, 1,25(\mathrm{OH})_{2} \mathrm{D}$ every 2 weeks during the first 10 weeks followed by measurements every 4 weeks; while intact FGF23, s-Klotho and pre- and postdialysis TnT will be measured at 8-week intervals). Furthermore, proBNP levels will be measured as a marker 


\begin{tabular}{|c|c|c|c|c|c|c|c|}
\hline Study phase & Screening & $\begin{array}{l}\text { Washout } \\
4 \text { weeks }\end{array}$ & $\begin{array}{l}\text { Base } \\
\text { line }\end{array}$ & $\begin{array}{l}\text { Alloc } \\
\text { ation }\end{array}$ & $\begin{array}{l}\text { Dose } \\
\text { titration } \\
16 \text { weeks }\end{array}$ & $\begin{array}{l}\text { Target drug } \\
\text { level } 36 \\
\text { weeks }\end{array}$ & $\begin{array}{l}\text { Close- } \\
\text { out }\end{array}$ \\
\hline \multirow[b]{2}{*}{ Randomization } & $\begin{array}{l}\text { Eligibility } \\
\text { screen, } \\
\text { Informed } \\
\text { consent }\end{array}$ & $\begin{array}{l}\text { If Vit D or } \\
\text { calcimimetic } \\
\text { in therapy }\end{array}$ & & & & & \\
\hline & & & & $\mathrm{x}$ & & & \\
\hline $\begin{array}{l}\text { Laboratory } \\
\text { analysis }\end{array}$ & $\mathrm{x}$ & & & & $\begin{array}{l}2 \text {-4 week- } \\
\text { intervals }\end{array}$ & $\begin{array}{l}4 \text { week } \\
\text { intervals }\end{array}$ & \\
\hline Strain Echo & $\mathrm{x}$ & & & & & & $\mathrm{X}$ \\
\hline Lung ultrasound & $x$ & & & & & & \\
\hline$B C M$ & $\mathrm{x}$ & & & & & $\begin{array}{l}8 \text { week } \\
\text { intervals }\end{array}$ & $\mathrm{x}$ \\
\hline cMRI & & & $\mathrm{x}$ & & & & $\mathrm{x}$ \\
\hline \multicolumn{8}{|l|}{ INTERVENTIONS } \\
\hline Etelcalcetide & & & & $\begin{array}{l}n=50 \\
\%\end{array}$ & & & \\
\hline Alfacalcidol & & & & $\begin{array}{l}n=50 \\
\%\end{array}$ & & & \\
\hline
\end{tabular}

Fig. 2 Study design. BCM body composition monitoring, CMRI cardiac magnetic resonance imaging, Echo echocardiography, Vit vitamin

of body fluid volume every 8 weeks. Additionally, an RAAS fingerprint will be conducted at the start and at the end of the treatment phase $[25,28,29,50]$. The RAAS fingerprint is a mass spectrometry-based quantification of angiotensin metabolites, which will be performed by a resident diagnostic service provider (Attoquant Diagnostics). Serum samples will be used to measure the following parameters: Ang I, Ang II, Ang-(1-7), Ang-(1-5), Ang-(1-9) and aldosterone.

Intact PTH, calcium and phosphate will be analyzed in serum samples using the Cobas assay (Roche; reference ranges: PTH $15-65 \mathrm{pg} / \mathrm{ml}$, calcium $2.15-2.55 \mathrm{mmol} / \mathrm{l}$ and phosphate $0.81-1.45 \mathrm{mmol} / \mathrm{l}$ ). Vitamin $\mathrm{D}$ will be measured using serum samples chemiluminescent immunoassays (DiaSorin; reference ranges: $1,25-(\mathrm{OH})_{2} \mathrm{D} 19.9-$ $79.3 \mathrm{pg} / \mathrm{ml}$ and $25(\mathrm{OH}) \mathrm{D} 75-250 \mathrm{nmol} / \mathrm{l})$. Ionized calcium will be measured during every dialysis session (using blood gas analysis (ABL 800 Flex, Drott)). Intact FGF23 will be analyzed in plasma samples using chemiluminescent immunoassays (DiaSorin; reference range: 23.2-95.4 pg/ml). TnT and proBNP will be measured from serum samples using Cobas electrochemiluminescence immunoassays
(Roche; reference ranges: TnT $0-14 \mathrm{ng} / \mathrm{L}$ and proBNP $0-$ $125 \mathrm{pg} / \mathrm{ml})$.

The timeline of the planned procedures, study visits and scheduled dose titrations is shown in Fig. 3.

\section{Investigational products}

The pharmacodynamics of ETL and cinacalcet are similar. They both cause rapid, dose-dependent decreases in circulating levels of PTH, FGF23, calcium and phosphorus in CKD patients.

A single intravenous dose of ETL can lower serum levels of PTH for up to $72 \mathrm{~h}$ in patients on hemodialysis. FGF23 levels decrease by over $30 \%$ at $24 \mathrm{~h}$ after a single 10-mg dose of ETL, while little or no effect is shown on $1,25(\mathrm{OH})_{2} \mathrm{D}$ levels in a study conducted by Martin et al. [51]. The most frequent treatment-emergent adverse event is a decrease in blood calcium [52]. ETL dosage should be between $2.5 \mathrm{mg}$ and $15 \mathrm{mg}$ three times a week. The starting dose is $5 \mathrm{mg}$ three times a week. To achieve a target value of PTH $(100-300 \mathrm{pg} / \mathrm{ml})$, the dosage will be adapted every 4 weeks in steps of 2.5 or $5 \mathrm{mg}$ during the titration phase. Serum calcium will be measured at 


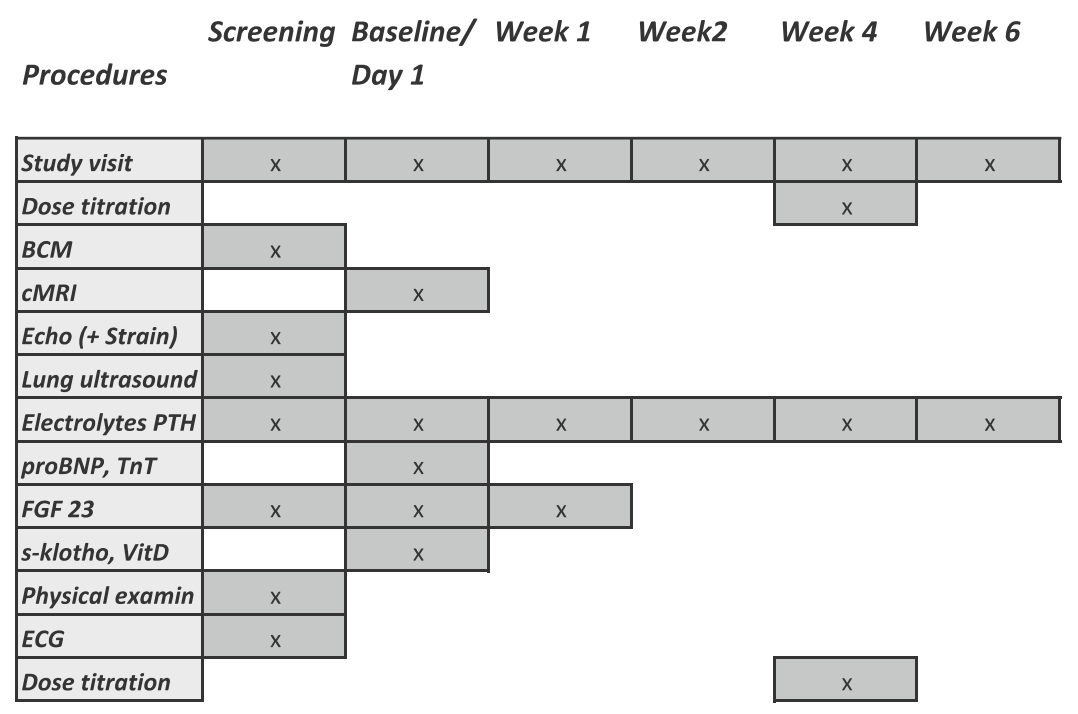

Week 8 Week 10 Week 12 Week 16 Week 20 Week 24

Procedures

\begin{tabular}{|c|c|c|c|c|c|c|}
\hline Study visit & $x$ & $x$ & $x$ & $x$ & $x$ & $\mathrm{x}$ \\
\hline Dose titration & $x$ & & $x$ & $x$ & & \\
\hline$B C M$ & $x$ & & & $x$ & & \\
\hline \multicolumn{7}{|l|}{ Lung ultrasound } \\
\hline Electrolytes PTH & $x$ & $x$ & $x$ & $x$ & $x$ & $\mathrm{x}$ \\
\hline proBNP, TnT & $x$ & & & $x$ & & \\
\hline FGF 23 & $x$ & & & $x$ & & \\
\hline s-klotho, Vit D & $x$ & & & $x$ & & \\
\hline Physical examin & & & & $x$ & & \\
\hline ECG & & & & $x$ & & \\
\hline Dose titration & $x$ & & $x$ & $x$ & & \\
\hline
\end{tabular}

Week 28 Week 32 Week 36 Week 40 Week 44 Week 48 Week 52/

Procedures

Last day

\begin{tabular}{|c|c|c|c|c|c|c|c|}
\hline Study visit & $x$ & $x$ & $x$ & $x$ & $x$ & $x$ & $x$ \\
\hline \multicolumn{8}{|l|}{ Dose titration } \\
\hline$B C M$ & & $x$ & & $x$ & & $x$ & \\
\hline cMRI & & & & & & & $x$ \\
\hline Echo (+ Strain) & & & & & & & $x$ \\
\hline \multicolumn{8}{|l|}{ Lung ultrasound } \\
\hline Electrolytes PTH & $x$ & $x$ & $x$ & $x$ & $x$ & $x$ & $x$ \\
\hline proBNP, TnT & & $x$ & & $x$ & & $x$ & \\
\hline FGF 23 & & $x$ & & $x$ & & $x$ & $x$ \\
\hline s-klotho, VitD & & $x$ & & $x$ & & $x$ & $x$ \\
\hline Physical examin & & $x$ & & & & & \\
\hline ECG & & $x$ & & & & & \\
\hline Dose titration & & & & & & & \\
\hline
\end{tabular}

Fig. 3 Study synopsis 
every dialysis session. Target levels of serum calcium corrected for serum albumin are $\geq 2.08 \mathrm{mmol} / \mathrm{l}$.

ALFA is an analogue of vitamin D3. ALFA can decrease PTH levels by $\geq 30 \%$ and increase FGF23 levels threefold [53]. In general, ALFA is a safe and welltolerated established treatment for SHPT.

The starting dose is $1 \mu \mathrm{g}$, administered as an intravenous bolus three times a week at the end of hemodialysis. ALFA dosage should be at least $0.5 \mu \mathrm{g}$ three times a week with no maximal dose. Titration will be performed in 0.5- to 1- $\mu$ g steps at 4-week intervals, depending on PTH values and serum calcium and phosphate levels. The target value of PTH is equivalent to the ETL group. Serum calcium corrected for serum albumin should be no higher than $2.55 \mathrm{mmol} / \mathrm{l}$ and serum phosphate levels should be below $2.5 \mathrm{mmol} / \mathrm{l}$.

The goal is to achieve a similar reduction in PTH in both study groups while FGF23 is elevated in the ALFA arm and suppressed in the ETL arm in order to analyze the causality of FGF23 reduction on LVH and fibrosis.

However, it is likely that the levels of PTH will vary, simply due to the different pharmacodynamics of the two drugs. Even though the dose of the study medication can be changed during the drug titration period as well as later on when necessary in order to reach target PTH levels, these adaptations are often limited by serum calcium and phosphate levels.

\section{Other HPT treatments}

Cinacalcet treatment as well as oral and intravenous vitamin $\mathrm{D}$ therapy will be discontinued during the washout phase of 4 weeks. Phosphate binder therapy can be continued and will be adapted depending on serum electrolytes during the treatment phase. There are no restrictions on calcium supplements, the dialysate calcium concentration, or the type or dose of phosphate binders prescribed. Participants randomized to ETL can receive additional vitamin $\mathrm{D}$ analogs as a rescue therapy only when the investigator thinks that it is necessary to protect participant safety.

\section{Data Safety Monitoring Board}

An independent Data Safety Monitoring Board of the Medical University of Vienna will be convened to assess the safety of treatment as well as the superiority of one treatment over the other $[54,55]$. Interim analysis will be performed by the board after the completed follow-up of 10 cases in each treatment group (one-third of the planned study population). The Lan and DeMets alpha spending method using O'Brien-Fleming type boundaries will be applied and the trial will be stopped if $p<0.000207$ [56].

\section{Quality control and quality assurance}

The study monitor will contact and visit the investigator regularly and will be allowed, on request, to have access to all source documents needed to verify the entries in the electronic documentation and other study-related documents provided that subject confidentiality is maintained in agreement with local regulations. It will be the monitor's responsibility to inspect the electronic case report forms at regular intervals throughout the study to verify the adherence to the study protocol and the completeness, consistency and accuracy of the data being entered. The monitoring standards require full verification for the presence of informed consent, adherence to the inclusion/exclusion criteria, documentation of serious adverse events (AEs)/serious adverse device effects and the recording of the main efficacy, safety, and tolerability endpoints. At least three monitoring visits are scheduled. The monitor will be working according to standard operating procedures and will provide a monitoring report after each visit for the sponsor and the investigator.

\section{Safety evaluation and reporting of adverse events}

The investigators ensure that adequate medical care is provided in any clinical situation, including emergencies. All AEs observed by the investigator or reported by subjects are to be properly captured in the subjects' medical records. This collection period will be from the time of the first dose of the investigational product to 30 days after the last dose.

It will be left to the investigator's clinical judgment to determine whether an $\mathrm{AE}$ is related and of sufficient severity to require the subject's removal from treatment. As defined by the International Conference on Harmonization guidelines and World Health Organization Good Clinical Practice guidelines, serious AEs are events that result in patient death, are lifethreatening, require or prolong hospital stay, cause persistent or significant disability or incapacity, result in congenital anomaly or birth defect, or necessitate specific interventions. Events that are suspected unexpected serious adverse reactions (SUSARs) will be reported to the responsible ethics committee - the European Medicines Agency via the Clinical Trials Coordination Center of the Medical University of Vienna. Fatal SUSARs will be reported as soon as possible, but at the latest within 7 days and nonfatal SUSARs within 15 days.

\section{Statistical methods}

Data will be described as means and standard deviation or medians and interquartile range for continuous symmetric and skewed variables, respectively. Distributions of the analyzed parameters will be visualized by boxplots and histograms. 
The primary endpoint (change in LVMI from baseline to 12 months) will be analyzed by the analysis of covariance. The main variable in the model to be tested will be treatment group, which represents the treatment effect on change in LVMI 1 year after baseline between the two treatments. Baseline LVMI for each patient will be used as a covariate in the model and the interaction between treatment group and baseline LVMI will be included. Furthermore, to account for stratification during randomization, the stratification factors will also be included in the model. The secondary endpoints (changes in FGF23, s-Klotho, PTH, 25(OH)D, $1,25(\mathrm{OH})_{2} \mathrm{D}$, proBNP, pre- and postdialysis TnT and RAAS metabolites) will be analyzed analogously. All analyses will be conducted according to the intention-to-treat principle. Two-sided $p$ values lower than 0.05 will indicate statistical significance.

\section{Sample size calculation}

On the assumption, based on published data, that the mean LVM/BSA of hemodialysis patients determined by cMRI is $100 \mathrm{~g} / \mathrm{m}^{2}$ with a standard deviation of $25 \mathrm{~g} / \mathrm{m}^{2}$ [42] and an expected treatment effect of delta LVMI of $20 \mathrm{~g} / \mathrm{m}^{2}, 25$ patients are needed per group to detect this difference with $80 \%$ power using a two-sample $t$ test at an alpha level of 0.05 . Assuming 10\% attrition (drop out/ loss to follow-up) within 1 year of follow-up, the final sample size in the intention-to-treat analysis will be 31 patients.

Patients receiving a renal transplant as well as those who become pregnant (which is unlikely due to the significantly reduced fertility of women under dialysis) will drop out of the study.

\section{Study registration}

The study was approved by the Austrian regulatory authority (Federal Office for Safety in Health Care, Austrian Agency for Health and Food Safety, AGES reference number 10087746) and was registered in the European Clinical Trials database (EudraCT, 2017-000222-35) and in a public clinical trial database (ClinicalTrials.gov, NCT03182699).

\section{Discussion}

In our proposed trial we will provide novel insights into the extent of FGF23-mediated cardiac remodeling in patients on chronic hemodialysis. We specifically hypothesize that treatment with ETL ameliorates pathological changes in the cardiac structure of dialysis patients with sHPT by suppression of systemic FGF23 levels.

The EVOLVE study investigated the effect of lowering FGF23 with the use of cinacalcet on cardiovascular mortality in 3883 hemodialysis patients with sHPT. They were able to show that a reduction in FGF23 of $\geq 30 \%$ after 20 weeks of therapy showed a trend towards a decrease in cardiovascular mortality, sudden cardiac death and heart failure $[35,57]$.

A small study conducted by Choi et al. described a significant reduction in LVMI and a significantly improved diastolic function, measured by echocardiography, in 12 hemodialysis patients treated with cinacalcet [58].

In our proposed trial we make use of the deviant influence of ETL versus ALFA on the serum levels of FGF23 since, as mentioned previously, calcimimetic drugs decrease FGF23 while vitamin D increases it. Consequently, we generated a human model to study the influence of changing serum FGF23 levels on cardiac structure using approved medication for SHPT. We established PTH target values of $100-300 \mathrm{pg} / \mathrm{ml}$ considering the Kidney Disease: Improving Global Outcomes guidelines in order to demonstrate the effect of FGF23 independent of PTH. Study medication will be provided intravenously, allowing a very consistent delivery of the drug. One of the most important advantages of the intravenous treatment is the elimination of possible noncompliance. Patient adherence to oral cinacalcet therapy is known to be very low [59]. Another major advantage of this study when comparing it to the trial by Choi et al. is the use of cMRI as the diagnostic tool for the quantification of left ventricular mass, lowering the inter- and intraobserver variability known from using echocardiography. cMRI provides accurate anatomic information that is in excellent agreement with autopsy results $[60,61]$. It is also able to detect LVH in patients with seemingly normal echocardiographic results due to a geometric assumption-free quantification of left ventricular mass [62, 63].

Based on the strong association of volume overload with CKD progression and adverse cardiac outcome we will perform a stratified randomization procedure to ensure an equal distribution of dialysis patients with residual renal function (i.e., $\geq 500 \mathrm{ml}$ urine/day) and those without $(<500 \mathrm{ml}$ urine/day) in both treatment groups [64]. Additionally, only patients reaching their individual optimal dry weight will be allowed to participate in the study.

This trial is designed to treat patients with either study medication for 12 months. It can be argued that this amount of time is too short to reproduce a measurable change in cardiac structure. It is important to consider that it takes a certain amount of time to develop SHPT under dialysis and to reach a severity requiring intravenous treatment. Additionally, in Austria the median time spent on the waiting list for renal transplantation is around 3 years, not to mention the high mortality of patients under dialysis. Consequently, in order to avoid a high drop-out as well as out-of-feasibility reasons, we decided this precise follow-up time period. 
The diagnosis of LVH prior to enrollment in the study poses a certain difficulty regarding the accuracy of echocardiographic quantification of LVH. However, since each patient serves as his or her own control, the progression of left ventricular mass can be demonstrated during the course of the 12 months of treatment.

This trial is designed to visualize changes in cardiac muscle mass and fibrosis as a result of modified FGF23 levels which might be causal to the improved cardiovascular outcomes under lower FGF23 described in the EVOLVE study. If our study proves that ETL can effectively ameliorate $\mathrm{LVH}$ and cardiac fibrosis trough a suppression of FGF23, it may potentially provide a valuable basis for a pharmaceutical target aiming at reducing the high rate of cardiac death in patients under maintenance hemodialysis.

\section{Trial status}

This is Protocol version 1.0, 28 May 2019. Recruitment of study patients started in October 2017 and enrollment is estimated to be complete as of November 2019.

\section{Supplementary information}

Supplementary information accompanies this paper at https://doi.org/10. 1186/s13063-019-3707-7.

Additional file 1. SPIRIT 2013 Checklist: Recommended items to address in a clinical trial protocol and related documents.

\section{Abbreviations}

1,25(OH) 2D: 1,25-Dihydroxyvitamin D; 25(OH)D: 25-Hydroxyvitamin D; ACE: Angiotensin-converting enzyme; AE: Adverse event; ALFA: Alfacalcidol; Ang: Angiotensin; BCM: Body composition monitoring; BNP: Brain natriuretic peptide; CKD: Chronic kidney disease; CMRI: Cardiac magnetic resonance imaging; ETL: Etelcalcetide; FGF: Fibroblast growth factor; FGFR: Fibroblast growth factor receptor; LVH: Left ventricular hypertrophy; LVM/BSA: Left ventricular mass indexed for body surface area; LVMI: Left ventricular mass index; PTH: Parathyroid hormone; RAAS: Renin-angiotensin-aldosterone system; SHPT: Secondary hyperparathyroidism; SUSAR: Suspected unexpected serious adverse reaction; TnT: Troponin T

\section{Acknowledgements}

We acknowledge the helpful contribution of the dialysis nursing staff of the Medical University of Vienna and the Vienna Dialysis Center. The research assistants Julia Wild, Anmoldeep Bhullar and Stefan Steinringer were helpful in implementing the complex logistics of this study.

\section{Authors' contributions}

$\mathrm{KD}, \mathrm{MK}$ and RO designed the study and wrote the draft of the manuscript. $\mathrm{ML}, \mathrm{CL}, \mathrm{RE}$ and RR-S provided feasibility expertise and data quality control. RM performed most laboratory measurements and contributed to data quality control. RO is the guarantor of this work and, as such, had full access to all the data in the study and takes responsibility for the integrity of the data and the accuracy of the data analysis. All authors read and approved the final manuscript.

\section{Funding}

Funding for this study was provided by the Vienna General Hospital (Amtsforschung) and an unrestricted grant from Amgen (reference 20167811).

\section{Availability of data and materials}

The data that support the findings of this study will be available from the corresponding author upon reasonable request.

\section{Ethics approval and consent to participate}

The study was approved by the Austrian regulatory authority (Federal Office for Safety in Health Care, Austrian Agency for Health and Food Safety, AGES reference number 10087746). The study will be conducted in accordance with the principles of the Declaration of Helsinki, 2008. Institutional ethics committee approval of the Medical University of Vienna (EK 1127/2017) and of the ethics committee of the Vienna Dialysis Center (05.09.2017) was obtained for all aspects of the study. All study participants will be asked to sign written informed consent in order to participate in the study (with patient insurance included).

\section{Consent for publication}

All authors approved the final manuscript and agreed to the submission. No individual personal data are contained in the manuscript.

\section{Competing interests}

The authors declare that they have no competing interests.

\section{Author details}

'Department of Nephrology, Medical University of Vienna, Spitalgasse 23, 1090 Vienna, Austria. ${ }^{2}$ Center for Medical Statistics, Informatics and Intelligent Systems (CeMSIIS), Section for Clinical Biometrics, Medical University of Vienna, Spitalgasse 23, 1090 Vienna, Austria. ${ }^{3}$ Vienna Dialysis Center, Kapellenweg 37, 1220 Vienna, Austria. ${ }^{4}$ Division of Cardiovascular and Interventional Radiology, Department of Bioimaging and Image-Guided Intervention, Medical University of Vienna, Spitalgasse 23, 1090 Vienna, Austria. ${ }^{5}$ Laboratory Medicine, Medical University of Vienna, Spitalgasse 23, 1090 Vienna, Austria. ${ }^{6}$ Physiology, Pathophysiology, and Experimental Endocrinology, VetMed Vienna, Veterinärplatz 1, Vienna, Austria.

Received: 6 August 2019 Accepted: 6 September 2019

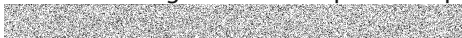

\section{References}

1. Di Marco GS, Reuter S, Kentrup D, Grabner A, Amaral AP, Fobker M, Stypmann J, Pavenstädt H, Wolf M, Faul C, Brand M. Treatment of established left ventricular hypertrophy with fibroblast growth factor receptor blockade in an animal model of CKD. Nephrol Dial Transplant. 2014:29:2028-34.

2. Faul C, Amaral AP, Oskouei B, Wolf M. FGF23 induces left ventricular hypertrophy. J Clin Invest. 2011:121:4393-408.

3. London GM, Pannier B, Guerin AP, Blacher J, Marchais SJ, Darne B, Metivier F. Adda H, Safar ME. Alterations of left ventricular hypertrophy in and survival of patients receiving hemodialysis: follow-up of an interventional study. J Am Soc Nephrol. 2001;12:2759-67.

4. Foley RN, Parfrey PS, Harnett JD, Kent GM, Martin CJ, Murray DC, Barre PE. Clinical and echocardiographic disease in patients starting end-stage renal disease therapy. Kidney Int. 1995;47:186-92.

5. Katz AM. Maladaptive growth in the failing heart: the cardiomyopathy of overload. Cardiovasc Drugs Ther. 2002;16:245-9.

6. Salerno MP, Rossi EL, Favi E, Pedroso JA, Spagnoletti G, Romagnoli J, Citterio $F$. The reduction of left ventricular hypertrophy after renal transplantation is not influenced by the immunosuppressive regimen. Transplant Proc. 2013; 45:2660-2.

7. Brilla $C G$, Pick R, Tan $L B$, Janicki JS, Weber $K T$. Remodeling of the rat right and left ventricles in experimental hypertension. Circ Res. 1990;67:1355-64.

8. Brilla CG, Rupp H, Funck R, Maisch B. The renin-angiotensin-aldosterone system and myocardial collagen matrix remodelling in congestive heart failure. Eur Heart J. 1995:16:107-9.

9. Shimada T, Hasegawa H, Yamazaki Y, Muto T, Hino R, Takeuchi Y, Fujita T, Nakahara K, Fukumoto S, Yamashita T. FGF-23 is a potent regulator of vitamin D metabolism and phosphate homeostasis. J Bone Miner Res. 2004; 19:429-35.

10. Wolf M, Molnar MZ, Amaral AP, Czira ME, Rudas A. Elevated fibroblast growth factor 23 is a risk factor for kidney transplant loss and mortality. J Am Soc Nephrol. 2011;22:956-66. 
11. Berndt TJ, Craig TA, McCormick DJ, Lanske B, Sitara D, Razzaque MS, Pragnell M, Bowe AE, O'Brien SP, Schiavi SC, Kumar R. Biological activity of FGF-23 fragments. Pflugers Arch. 2007;454:615-23.

12. Larsson $T$, Nisbeth UL, Ljunggren Ö, Jueppner $H$, Jonsson KB. Circulating concentration of FGF-23 increases as renal function declines in patients with chronic kidney disease, but does not change in response to variation in phosphate intake in healthy volunteers. Kidney Int. 2003;64:2272-9.

13. Gutierrez O, Isakova T, Rhee E, Shah A, Holmes J, Collerone G, Juppner H, Wolf M. Fibroblast growth factor-23 mitigates hyperphosphatemia but accentuates calcitriol deficiency in chronic kidney disease. J Am Soc Nephrol. 2005;16:2205-15.

14. Shigematsu T, Kazama JJ, Yamashita T, Fukumoto S, Hosoya T, Gejyo F, Fukagawa M. Possible involvement of circulating fibroblast growth factor 23 in the development of secondary hyperparathyroidism associated with renal insufficiency. Am J Kidney Dis. 2004;44:250-6.

15. Pavik I, Jaeger P, Ebner L, Wagner CA, Serra AL. Secreted Klotho and FGF23 in chronic kidney disease stage 1 to 5 : a sequence suggested from a crosssectional study. Nephrol Dial Transplant. 2012;28:352-9.

16. Grabner A, Amaral AP, Schramm K, Singh S, Wolf M, Faul C. Activation of cardiac fibroblast growth factor receptor 4 causes left ventricular hypertrophy. Cell Metab. 2015;22:1020-32

17. Andrukhova O, Slavic S, Smorodchenko A, Zeitz U, Shalhoub V, Lanske B, Pohl EE, Erben RG. FGF23 regulates renal sodium handling and blood pressure. EMBO Mol Med. 2014;6:744-59.

18. Andrukhova O, Slavic S, Odörfer KI, Erben RG. Experimental myocardial infarction upregulates circulating fibroblast growth factor-23. J Bone Miner Res. 2015;30:1831-9.

19. Andrukhova O, Smorodchenko A, Egerbacher M, Streicher C, Zeitz U, Goetz R, Shalhoub V, Mohammadi M, Pohl EE, Lanske B, Erben RG. FGF23 promotes renal calcium reabsorption through the TRPV5 channel. EMBO J. 2014;33:229-46.

20. Slavic S, Ford K, Modert M, Becirovic A, Handschuh S, Baierl A, Katica N, Zeitz U, Erben RG, Andrukhova O. Genetic ablation of FGF23 or Klotho does not modulate experimental heart hypertrophy induced by pressure overload. Sci Rep. 2017;7:11298

21. Crackower MA, Sarao R, Oudit GY, Yagil C, Kozieradzki I, Scanga SE, Oliveirados-Santos AJ, da Costa J, Zhang L, Pei Y, Scholey J, Ferrario CM, Manoukian AS, Chappell MC, Backx PH, Yagil Y, Penninger JM. Angiotensin-converting enzyme 2 is an essential regulator of heart function. Nature. 2002;417:822-8.

22. Gurley SB, Allred A, Le TH, Griffiths R, Mao L, Philip N, Haystead TA, Donoghue M, Breitbart RE, Acton SL, Rockman HA, Coffman TM. Altered blood pressure responses and normal cardiac phenotype in ACE2-null mice. J Clin Invest. 2006;116:2218-25.

23. Rentzsch B, Todiras M, lliescu R, Popova E, Campos LA, Oliveira ML, Baltatu OC, Santos RA, Bader M. Transgenic angiotensin-converting enzyme 2 overexpression in vessels of SHRSP rats reduces blood pressure and improves endothelial function. Hypertension. 2008:52:967-73.

24. Wysocki J, Ye M, Rodriguez E, González-Pacheco FR, Barrios C, Evora K, Schuster M, Loibner H, Brosnihan KB, Ferrario CM, Penninger JM, Batlle D. Targeting the degradation of angiotensin II with recombinant angiotensinconverting enzyme 2: prevention of angiotensin II-dependent hypertension. Hypertension. 2010;55:90-8.

25. Zhao YX, Yin HQ, Yu QT, Qiao Y, Dai HY, Zhang MX, Zhang L, Liu YF, Wang LC, Liu DS, Deng BP, Zhang YH, Pan CM, Song HD, Qu X, Jiang H, Liu CX, Lu $X T$, Liu B, Gao F, Dong B. ACE2 overexpression ameliorates left ventricular remodeling and dysfunction in a rat model of myocardial infarction. Hum Gene Ther. 2010;21:1545-54.

26. Grobe JL, Der Sarkissian S, Stewart JM, Meszaros JG, Raizada MK, Katovich MJ. ACE2 overexpression inhibits hypoxia-induced collagen production by cardiac fibroblasts. Clin Sci (Lond). 2007;113:357-64.

27. Huentelman MJ, Grobe JL, Vazquez J, Stewart JM, Mecca AP, Katovich MJ, Ferrario CM, Raizada MK. Protection from angiotensin II-induced cardiac hypertrophy and fibrosis by systemic lentiviral delivery of ACE2 in rats. Exp Physiol. 2005;90:783-90.

28. Iwata M, Cowling RT, Gurantz D, Moore C, Zhang S, Yuan JX, Greenberg BH. Angiotensin-(1-7) binds to specific receptors on cardiac fibroblasts to initiate antifibrotic and antitrophic effects. Am J Physiol Heart Circ Physiol. 2005;289:2356-63.

29. Grobe JL, Mecca AP, Lingis M, Shenoy V, Bolton TA, Machado JM, Speth RC, Raizada MK, Katovich MJ. Prevention of angiotensin II-induced cardiac remodeling by angiotensin-(1-7). Am J Physiol Heart Circ Physiol. 2007;292:736-42.
30. Weber KT, Brilla CG. Pathological hypertrophy and cardiac interstitium. Fibrosis and renin-angiotensin-aldosterone system. Circulation. 1991;83: 1849-65.

31. Sciarretta S, Paneni F, Palano F, Chin D, Tocci G, Rubattu S, Volpe M. Role of the renin-angiotensin-aldosterone system and inflammatory processes in the development and progression of diastolic dysfunction. Clin Sci (Lond). 2009;116:467-77.

32. Mathew J, Sleight P, Lonn E, Johnstone D, Pogue J, Yi Q, Bosch J, Sussex B, Probstfield J, Yusuf S, Heart Outcomes Prevention Evaluation (HOPE) Investigators. Reduction of cardiovascular risk by regression of electrocardiographic markers of left ventricular hypertrophy by the angiotensin-converting enzyme inhibitor ramipril. Circulation. 2001; 104:1615-21.

33. Chonchol M, Greene T, Zhang Y, Hoofnagle AN, Cheung AK. Low vitamin D and high fibroblast growth factor 23 serum levels associate with infectious and cardiac deaths in the HEMO study. J Am Soc Nephrol. 2016;27:227-37.

34. Kim HJ, Kim H, Shin N, Na KY, Kim YL, Kim D, Chang JH. Cinacalcet lowering of serum fibroblast growth factor-23 concentration may be independent from serum $\mathrm{Ca}, \mathrm{P}, \mathrm{PTH}$ and dose of active vitamin $\mathrm{D}$ in peritoneal dialysis patients: a randomized controlled study. BMC Nephrol. 2013;14:112.

35. EVOLVE Trial Investigators, Chertow GM, Block GA, Correa-Rotter R, Drüeke TB, Floege J, Goodman WG, Herzog CA, Kubo Y, London GM, Mahaffey KW, Mix TC, Moe SM, Trotman ML, Wheeler DC, Parfrey PS. Effect of cinacalcet on cardiovascular disease in patients undergoing dialysis. N Engl J Med. 2012:367:2482-94.

36. Sprague ST, Wetmore JB, Gurevich K, Da Roza G. Effect of cinacalcet and vitamin $D$ analogs on fibroblast growth factor-23 during the treatment of secondary hyperparathyroidism. Clin J Am Soc Nephrol. 2015;367:2482-94.

37. Wetmore JB, Gurevich K, Sprague S, Da Roza G, Buerkert J, Reiner M, Goodman W, Cooper K. A randomized trial of cinacalcet versus vitamin D analogs as monotherapy in secondary hyperparathyroidism (PARADIGM). Clin J Am Soc Nephrol. 2015;10:1031-40.

38. Jambrik Z, Monti S, Coppola V, Agricola E, Mottola G, Miniati M, Picano E. Usefulness of ultrasound lung comets as a nonradiologic sign of extravascular lung water. Am J Cardiol. 2004;93:1265-70.

39. Agricola E, Bove T, Oppizzi M, Marino G, Zangrillo A, Margonato A, Picano E. "Ultrasound comet-tail images": a marker of pulmonary edema, a comparative study with wedge pressure and extravascular lung water. Chest. 2005;127:1690-5.

40. MoissI UM, Wabel P, Chamney PW, Bosaeus I, Levin NW, Bosy-Westphal A, Korth O, Müller MJ, Ellegård L, Malmros V, Kaitwatcharachai C, Kuhlmann MK Zhu F, Fuller NJ. Body fluid volume determination via body composition spectroscopy in health and disease. Physiol Meas. 2006:27:921-33.

41. Keane D, Chamney P, Heinke S, Lindley E. Use of the body composition monitor for fluid status measurements in subjects with high body mass index. Nephron. 2016;133:163-8.

42. Patel RK, Oliver S, Mark PB, Powell JR, McQuarrie EP, Traynor JP, Dargie HJ, Jardine AG. Determinants of left ventricular mass and hypertrophy in hemodialysis patients assessed by cardiac magnetic resonance imaging. Clin J Am Soc Nephrol. 2009;4:1477-83.

43. Sparrow P, Messroghli DR, Reid S, Ridgway JP, Bainbridge G, Mohan U. Myocardial T1 mapping for detection of left ventricular myocardial fibrosis in chronic aortic regurgitation: pilot study. Am J Roentgenol. 2006;187:630-5.

44. Graham-Brown MP, March DS, Churchward DR, Stensel DJ, Singh A, Arnold R, Burton JO, McCann GP. Novel cardiac nuclear magnetic resonance method for noninvasive assessment of myocardial fibrosis in hemodialysis patients. Kidney Int. 2016;90:835-44.

45. Haland TF, Almaas VM, Hasselberg NE, Saberniak J, Leren IS, Hopp E, Edvardsen T, Haugaa KH. Strain echocardiography is related to fibrosis and ventricular arrhythmias in hypertrophic cardiomyopathy. Eur Heart J Cardiovasc Imaging. 2016;17:613-21.

46. Jellies C, Martin J, Narula J, Marwick TH. Assessment of nonischemic myocardial fibrosis. J Am Coll Cardiol. 2010;56:89-97.

47. Saito M, Okayama H, Yoshii T, Higashi H, Morioka H, Hiasa G, Sumimoto T, Inaba S, Nishimura K, Inoue K, Ogimoto A, Shigematsu Y, Hamada M, Higaki J. Clinical significance of global two-dimensional strain as a surrogate parameter of myocardial fibrosis and cardiac events in patients with hypertrophic cardiomyopathy. Eur Heart J Cardiovasc Imaging. 2012;13:617-23.

48. Koell B, Zotter-Tufaro C, Duca F, Kammerlander A, Aschauer S, Dalos D, Antlanger M, Hecking M, Säemann M, Mascherbauer J. Fluid status and 
outcome in patients with heart failure and preserved ejection fraction. Int J Cardiol. 2017;230:476-81.

49. Picano E, Frassi F, Agricola E, Gligorova S, Gargani L, Mottola G. Ultrasound lung comets: a clinically useful sign of extravascular lung water. J Am Soc Echocardiogr. 2006;19:356-63.

50. Kovesdy CP, Quarles LD. FGF23 from bench to bedside. Am J Physiol Renal Physiol. 2016;310:1168-74.

51. Martin KJ, Bell G, Pickthorn K, Huang S, Vick A, Hodsman P, Peacock M. Velcalcetide (AMG 416), a novel peptide agonist of the calcium-sensing receptor, reduces serum parathyroid hormone and FGF23 levels in healthy male subjects. Nephrol Dial Transplant. 2014;29:385-92.

52. Nemeth EF, Goodman WG. Calcimimetic and calcilytic drugs: feats, flops, and futures. Calcif Tissue Int. 2015;98:341-58.

53. Hansen D, Rasmussen K, Pedersen SM, Rasmussen LM, Bandi L. Changes in fibroblast growth factor 23 during treatment of secondary hyperparathyroidism with alfacalcidol or paricalcitol. Nephrol Dial Transplant. 2012;27:2263-9.

54. O'Brien PC, Fleming TR. A multiple testing procedure for clinical trials. Biometrics. 1979:35:549-56.

55. Lan KKG, DeMets DL. Discrete sequential boundaries for clinical trials. Biometrika. 1983;70(3):659-63.

56. DeMets $\mathrm{DL}$, Lan KG. Interim analysis: the alpha spending function approach. Stat Med. 1994;13:1341-52

57. Moe SM, Chertow GM, Parfrey PS, Kubo Y, Block GA, Correa-Rotter R, Drüeke TB, Herzog CA, London GM, Mahaffey KW, Wheeler DC. Cinacalcet, fibroblast growth factor-23, and cardiovascular disease in hemodialysis: the evaluation of cinacalcet $\mathrm{HCl}$ therapy to lower cardiovascular events (EVOLVE) trial. Circulation. 2015;132:27-39.

58. Choi SR, Lim JH, Kim MY, Hong Y-A, C.W.P. Cinacalcet improves endothelial dysfunction and cardiac hypertrophy in patients on hemodialysis with secondary hyperparathyroidism. Nephron Clin Pract. 2012;122:1-8.

59. Gincherman Y, Moloney K, McKee C, Coyne DW. Assessment of adherence to cinacalcet by prescription refill rates in hemodialysis patients. Hemodial Int. 2010;14:68-72.

60. MacDonald KA, Kittleson MD, Reed T, Larson R, Kass P, Wisner ER. Quantification of left ventricular mass using cardiac magnetic resonance imaging compared with echocardiography in domestic cats. Vet Radiol Ultrasound. 2005;46:192-9.

61. Lorenz CH, Walker ES, Morgan VL, Klein SS, Graham TP Jr. Normal human right and left ventricular mass, systolic function, and gender differences by cine magnetic resonance imaging. J Cardiovasc Magn Reson. 1999;1:7-21.

62. Bogazzi F, Lombardi M, Strata E, Aquaro G, Di Bello V, Cosci C, Sardella C, Talini E, Martino E. High prevalence of cardiac hypertophy without detectable signs of fibrosis in patients with untreated active acromegaly: an in vivo study using magnetic resonance imaging. Clin Endocrinol (Oxf). 2008; 68:361-8

63. Celebi AS, Yalcin H, Yalcin F. Current cardiac imaging techniques for detection of left ventricular mass. Cardiovasc Ultrasound. 2010;8:19.

64. Hung SC, Lai YS, Kuo KL, Tarng DC. Volume overload and adverse outcomes in chronic kidney disease: clinical observational and animal studies. J Am Heart Assoc. 2015;4(5). https://doi.org/10.1161/JAHA.115.001918.

\section{Publisher's Note}

Springer Nature remains neutral with regard to jurisdictional claims in published maps and institutional affiliations.

Ready to submit your research? Choose BMC and benefit from:

- fast, convenient online submission

- thorough peer review by experienced researchers in your field

- rapid publication on acceptance

- support for research data, including large and complex data types

- gold Open Access which fosters wider collaboration and increased citations

- maximum visibility for your research: over $100 \mathrm{M}$ website views per year

At BMC, research is always in progress.

Learn more biomedcentral.com/submissions 